\title{
Malaria incidence and assessment of entomological indices among resettled communities in Ethiopia: a longitudinal study
}

\author{
Teshome Degefa', Ahmed Zeynudin', Ameyu Godesso ${ }^{2}$, Yohannes Haile Michael $^{3}$, Kasahun Eba ${ }^{4}$, \\ Endalew Zemene ${ }^{1}$, Daniel Emana ${ }^{1}$, Belay Birlie ${ }^{5}$, Kora Tushune ${ }^{3}$ and Delenasaw Yewhalaw ${ }^{1 *}$
}

\begin{abstract}
Background: Population resettlement has been considered among factors that may increase risk of malaria transmission. This study reports, the impact of resettlement on malaria incidence and entomological indices among communities resettled in suburbs of Jimma town, southwestern Ethiopia.

Methods: A cohort of 604 study participants (302 resettlers and 302 non-resettlers) was monthly followed-up from September to November 2013 using active case detection. Moreover, longitudinal entomological study was conducted from June to November 2013. Anopheline mosquitoes were collected using CDC light traps and pyrethrum spray catches. Sporozoite ELISA was performed to determine Plasmodium infection rates.

Results: Overall, 112 malaria cases were recorded during the three-month follow-up, of which $74.1 \%$ of the cases were from resettlement villages. Plasmodium falciparum incidence from resettlement and non-resettlement villages was 52.5 and 14.5/1,000 person-months at risk, respectively. Resettlement villages were three times at higher risk of Plasmodium infection $(\mathrm{OR}=2.8,95 \% \mathrm{Cl}: 1.22-6.48)$. Anopheles gambiae s.l. was the predominant (86.6\%) of all the collected anopheline mosquito species. Plasmodium sporozoite rate in the resettlement and non-resettlement villages was 2.1 and $0.72 \%$, respectively. Plasmodium falciparum entomological inoculation rate (EIR) for An. gambiae s.l. in the resettlement and non-resettlement villages was 13.1 and 0 infective bites/person/night, respectively. Both sporozoite rate and EIR were significantly higher in the resettlement villages $(p<0.05)$.
\end{abstract}

Conclusion: Resettled communities were at higher risk of malaria infection as compared to non-resettled communities. Special attention should be given to malaria control interventions during resettlement programmes.

Keywords: Malaria, Incidence, Anopheles, Entomological indices, Resettlement, Ethiopia

\section{Background}

Malaria is a serious problem in Ethiopia, where about 68\% of the population lives in malaria-risk areas. It is endemic in Ethiopia with differing intensity of transmission, except in the central highlands, which are malaria-free. In 2009, three million suspected malaria cases were recorded and nearly 2.3 million (77\%) were tested. Besides the individual suffering caused by the disease, malaria poses a significant economic burden in Ethiopia [1,2].

\footnotetext{
* Correspondence: delenasawye@yahoo.com

${ }^{1}$ Department of Medical Laboratory Sciences and Pathology, College of Public Health and Medical Sciences, Jimma University, Jimma, Ethiopia Full list of author information is available at the end of the article
}

Malaria showed a decline in Ethiopia over the last ten years as a result of high coverage of key malaria control interventions. This is attributable to the introduction of artemisinin-based combination therapy (ACT), use of rapid diagnostic tests (RDTs) at the peripheral health facilities, wide-scale distribution of long-lasting insecticidal nets (LLINs) and high coverage of sprayed households through targeted indoor residual spraying since 2004/2005 [3]. The National Malaria Indicator Survey (MIS) also showed that malaria declined in the country [4]. Shargie et al. [5] reported that malaria in Ethiopia decreased from 4.1\% in 2006 to $0.4 \%$ in 2007 following scale-up of LLINs and large rollout of ACT. Jima et al. [6] also reported that malaria inpatient admissions and deaths declined threefold between 
2005 and 2009. Inpatient malaria cases and deaths in children less than 5 years of age reduced by $73 \%$ and $62 \%$, respectively in Ethiopia [7]. However, the high influx of nonimmune people into malaria endemic areas for social and economic reasons such as resettlement and search for alternative income, and the expansion of agricultural and other development projects could alter the number of malaria cases and malaria incidence.

In Ethiopia, information on the impact of resettlement on malaria incidence and transmission is scarce. However, few studies conducted in Pawe area, Northwest Ethiopia documented the emergence of malaria following resettlement schemes [8-10]. Currently, several urban development projects are underway in different parts of Ethiopia. In Jimma town, development projects such as road construction, airport expansion, housing, expansion of industrial zone and governmental institutions like schools and health facilities are being carried out. These development project activities resulted in resettlement of people from the centre to the suburbs of the town. The resettlement could result in ecological transformation, which in turn may affect malaria incidence and transmission dynamics. Therefore, the aim of this study was to investigate the impact of the resettlement on malaria incidence and transmission intensity in Jimma town, southwestern Ethiopia.

\section{Methods}

\section{Study setting}

The study was carried out in two resettlement and two control (non-resettlement) villages of Jimma town, southwest Ethiopia (Figure 1). Jimma town is located $350 \mathrm{~km}$ southwest of Addis Ababa. The geographical coordinates of the town are approximately $7^{\circ} 41^{\prime} \mathrm{N}$ latitude and $36^{\circ} 50^{\prime} \mathrm{E}$ longitude. The resettlement villages are Barkume and Kito while the control villages are Boye and Cheshire. All villages are suburbs of Jimma town. Communities resettled in the two resettlement villages in 2008. The resettlement was mainly due to airport expansion, road construction, expansion of school and health facility, industrialization and flooding problems at the centre of the town.

The control villages were selected purposefully based on the following criteria: i) Comparable socio-economic condition between resettlement and non-resettlement villages ii) Similarity in eco-topography between resettlement and non-resettlement villages, iii) Minimum distance of $3 \mathrm{~km}$ between the two villages considering anopheline mosquito's flight range, iv) Similarity in climate.

Jimma town is characterized by warm climate with a mean annual minimum and maximum temperature of $14^{\circ} \mathrm{C}$ and $30^{\circ} \mathrm{C}$, respectively. The mean annual rainfall ranges from 1,138 to $1,690 \mathrm{~mm}$. Maximum precipitation

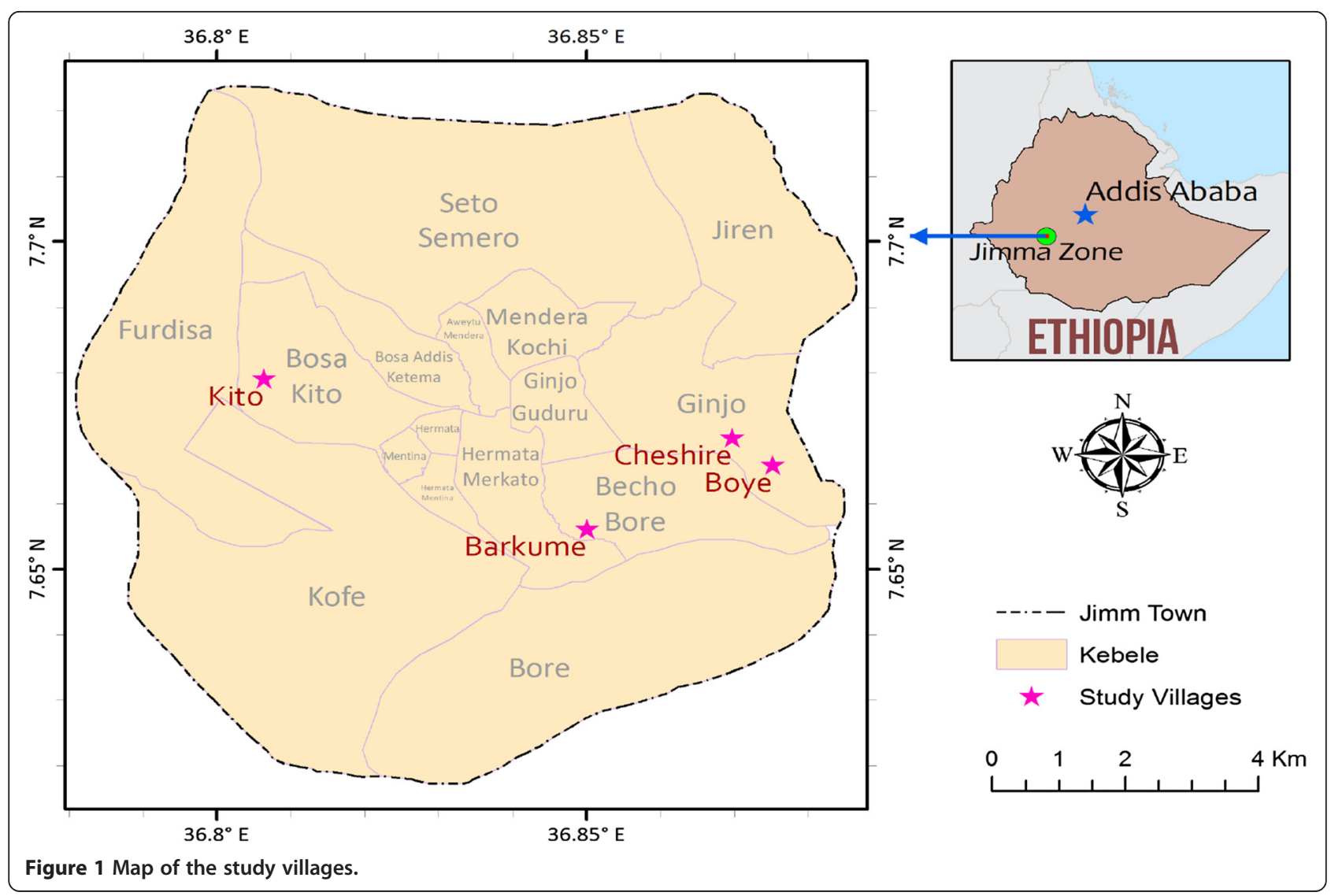


occurs during the three months (June to August), with minimum precipitation in December and January (National Meteorological Agency, Unpublished data).

\section{Study design and period}

For parasitological survey, community-based cohort study was conducted using active case detection from September 1 to November 30, 2013. Moreover, longitudinal entomological study was conducted from June to November, 2013.

\section{Study participants and sampling}

A cohort of 604 (302 from resettlement and 302 from non-resettlement villages) individuals residing in 202 households was followed-up. The sample size was determined using the formula for two population proportion with the following assumptions: Resettlement was considered as an exposure factor, previous malaria prevalence of $5.2 \%$ in Jimma town [11] was considered as an outcome in non-resettlement villages, 95\% confidence level, $80 \%$ power and anticipated risk ratio of $2.96[8,10]$. Dropout rate of $10 \%$ and design effect of two (to adjust for clustering effect) were considered, which finally gave a sample size of 604 individuals.

Households were selected from each village by dividing the sample size to the average family size of the town [12]. Census of the resettlement villages was done prior to data collection and list of households of the nonresettlement villages was obtained from the kebele administration. Finally, simple random sampling was employed to select households from each village. All family members in the selected households fulfilling the inclusion criteria were enrolled in the study. Inclusion criteria of the study participants were: intention to remain in the study area for the duration of study followup, willingness to participate in the study and being permanent resident (in non-resettlement villages) and resettler since 2008 (in resettlement villages). Individuals who were taking anti-malarial drugs at the baseline were excluded from the study.

\section{Socio-demographic data collection}

Baseline data on socio-demographic and economic characteristics of each household member, use of malaria preventive measures and ownership of domestic animals were collected using semi-structured questionnaire. Presence and distance of temporary vector breeding sites from each household were recorded monthly.

\section{Parasitological survey}

Parasitological data were collected by active case detection. A unique identification card was given to each household member. Each study participant was visited monthly for three months. During monthly house-to-house visit, blood sample was collected from the study participants following standard protocol [13]. Thick and thin blood films were prepared, stained with $10 \%$ Giemsa and examined at Medical Parasitology Laboratory in Jimma University. Experienced laboratory technologist examined the slides using oil immersion objective. All positive slides and $10 \%$ of the negative slides were re-examined by another blinded senior laboratory technologist.

\section{Entomological survey}

Adult anopheline mosquitoes were collected from both resettlement and non-resettlement villages. For the indoor mosquito sampling, adult anopheline mosquitoes resting inside human habitations were collected monthly from 10 selected houses per village using pyrethrum spray catches (PSCs) and from two houses per village at fortnight interval using Centers for Disease Control and Prevention (CDC) light trap catches (LTCs) (John W. Hock Ltd, Gainesville, FL., USA).

Pyrethrum spray catches were conducted early in the morning from 06:00 to 08:00 hr. White sheets of cloth and Baygon aerosol (SC. Johnson \& Son. Inc, USA) were used for the spray. After obtaining consent from the inhabitants, foodstuff and utensils were removed before spraying. Openings and eves which allow mosquito escape from houses were covered and white sheets were spread over the floor. Finally, rooms were sprayed with the aerosol for about 10 minutes. After 15 minutes following spraying, the sheet was removed and taken outside to inspect and collect the knockdown mosquitoes. CDC light trap was set indoor near the bed at a height of 1.5 meter from 18:00 to 06:00 hr in the selected houses to collect endophagic anopheline mosquitoes. For the outdoor mosquito sampling, CDC light trap was also set in the vicinity of sentinel houses from 18:00 to 06:00 hr.

The collected mosquitoes were transported to the Vector Biology Laboratory and sorted by genus and sex. The mosquitoes were morphologically identified to species using taxonomic keys $[14,15]$. Female anopheline mosquitoes were kept individually in eppendorf tube over silica gel for further processing.

\section{Sporozoite ELISA}

Dried head and thorax of the preserved anopheline mosquito specimens were carefully separated from the abdomen and tested for Plasmodium falciparum, Plasmodium vivax 210 and $P$. vivax 247 circumsporozoite proteins (CSPs) simultaneously using ELISA [16,17].

\section{Data analysis}

Data were coded, checked for completeness and entered into a computer. The data were then analysed using SPSS software package version 16.0 (SPSS, Chicago, IL, USA). At baseline, household and individual-level comparison was made in terms of socio-demographic and socio- 
economic characteristics between resettlement and nonresettlement villages using chi-square test. Plasmodium falciparum incidence rates were estimated as the number of cases per 1000 person-months at risk.

Generalized liner mixed effect model (GLMM) was used to compare the risk of Plasmodium infection between resettlement and non-resettlement villages. Let $Y_{\mathrm{ijk}}$ be the $\mathrm{k}^{\text {th }}$ binary outcome measure (malaria status) for individual (IND) $j$ living in household (HH) $i$. The following three-level logistic mixed model was considered which accounted for the clustering of the outcomes within individuals and households.

$$
\begin{aligned}
Y_{i j k} \sim \operatorname{Bernoulli}\left(\pi_{i j k}\right) \operatorname{logit}\left(\pi_{i j k}\right)=\log \left(\frac{\pi_{i j k}}{1-\pi_{i j k}}\right) \\
=\beta_{0}+\beta_{1} x_{i 1}+\ldots+\beta_{k} x_{i k}+a_{i} \\
\quad+b_{j(i)}, a_{i} \sim N\left(0, \delta_{H H}^{2}\right), b_{j(i)} \sim N\left(0, \delta_{I N D}^{2}\right)
\end{aligned}
$$

The household effects $a_{\mathrm{i}}$ represent the fact that some households are more successful in utilizing protective methods for malaria than others. The individual effects $b_{j(i)}$ represent the fact that susceptibility to Plasmodium infection is not the same among individuals. Thus, comparison between resettlement and non-resettlement villages was adjusted for the possible confounding factors such as age, gender, distance from vector breeding site, insecticide-treated nets (ITNs), indoor residual spraying (IRS), presence of domestic animals in or around the houses, family size and type of house.

The sporozoite rate was estimated as the proportion of mosquitoes positive for $P$. falciparum and $P$. vivax of the total number of mosquitoes tested. Monthly Plasmodium EIRs of Anopheles gambiae s.l. was calculated from mosquito collections by LTCs using the standard formula, $1.605 \times$ (no. circumsporozoite-positive ELISA results from CDC LTCs/no. mosquitoes tested) $\times$ (no. mosquitoes collected from CDC LTCs/no. catches) $\times$ No. days per month [18].

Analysis of variance was employed to compare resettlement and non-resettlement villages in terms $A n$. gambiae s.l. density, sporozoite rate and EIRs. SPSS version 16.0 (SPSS, Chicago, IL, USA) and SAS version 9.3 (SAS, Cary, NC, USA) statistical software packages were used for the analysis. $\mathrm{p}<0.05$ was considered significant during the analysis.

\section{Ethical clearance}

Ethical clearance was obtained from the Research and Ethics Review Committee of Jimma University. Permission was sought from Jimma Town Health Office. Written informed consent was obtained from heads of the households and parents/guardians for children. During parasitological survey, participants found positive were treated according to the national malaria diagnosis and treatment guideline.

\section{Results}

Socio-demographic characteristics of the study

\section{participants}

Table 1 shows the socio-demographic and socio-economic characteristics of the study participants. A cohort of 604 study participants residing in 202 households was followedup in the longitudinal parasitological study. Of the total households interviewed, 134 (66.3\%) were females and 68 (33.7\%) were males. The majority of the households (83.2\%) were married and their mean age was 33.5 years. The mean family size was 4.49 . There was no significant difference in socio-economic status of the households between resettlement and non-resettlement villages $(\mathrm{p}>0.05)$. The majority (92.1\%) of the houses were mud plastered. Most of the study households in the resettlement villages (62.4\%) were located $<1 \mathrm{~km}$ from mosquito breeding sites. The majority of households $(63.4 \%)$ reported to have at least one ITN. Moreover, $86.1 \%$ of the households reported that their houses were sprayed with insecticides. There was significant difference in the type of house and distance of houses from mosquito breeding site between the resettlement and non-resettlement villages $(\mathrm{p}<0.05)$.

The majority $(57.1 \%)$ of the participants were females. Fifty seven percent of the study participants were above the age of 14 years followed by age groups 5-14 (30.5\%) and $<5$ years $(12.5 \%)$ with mean age of 21 years. The difference in gender and age of the study participants between resettlement and non-resettlement villages was not significant $(p>0.05)$.

\section{Parasitological survey}

All of the study participants completed the first and second round of parasitological survey while $22(3.7 \%)$ were lost to follow-up during the third round survey. The overall prevalence of malaria was 112 (6.3\%). Plasmodium falciparum, P. vivax and mixed infections accounted for 58 (51.8\%), 52 (46.4\%) and $2(1.8 \%)$ of the total cases, respectively.

Eighty three $(74.1 \%)$ and $29(25.9 \%)$ of the malaria cases were from the resettlement and non-resettlement villages, respectively. The majority of $P$. falciparum $(77.6 \%)$ and $P$. vivax (69.2\%) cases and two of the cases due to mixed infections were from resettlement villages. Figure 2 shows malaria incidence in the study villages. Overall, $P$. falciparum incidence was 33.5/1,000 person-months at risk, with $52.5 / 1,000$ and 14.5/1,000 person-months at risk incidence in resettlement and non-resettlement villages, respectively.

Table 2 shows a generalized linear mixed regression model for comparison of Plasmodium infection between resettlement and non-resettlement villages. The difference in the risk of Plasmodium infection between resettlement and non-resettlement villages was significant $\left(x^{2}=27.64, \mathrm{p}<\right.$ $0.05)$. Individuals living in the resettlement villages were three times at higher risk of malaria infection $(\mathrm{OR}=2.807$, 95\% CI: 1.22-6.48). House structure and family size were the 
Table 1 Socio-demographic and socio-economic characteristics of heads of the households, Jimma town, Southwest Ethiopia

\begin{tabular}{|c|c|c|c|c|c|}
\hline \multirow[t]{2}{*}{ Variables } & & \multicolumn{3}{|l|}{ Village type } & \multirow[t]{2}{*}{$p$-value } \\
\hline & & Resettlement & Non-resettlement & Total & \\
\hline \multirow{3}{*}{ Gender } & & & & & \\
\hline & Male & $31(45.6)$ & $37(54.4)$ & $68(100.0)$ & 0.372 \\
\hline & Female & $70(52.2)$ & $64(47.8)$ & $134(100.0)$ & \\
\hline \multirow[t]{3}{*}{ Age group (years) } & $18-25$ & $29(43.9)$ & $37(56.1)$ & $66(100.0)$ & 0.484 \\
\hline & $26-30$ & $23(52.3)$ & $21(47.7)$ & $44(100.0)$ & \\
\hline & $>30$ & $49(53.3)$ & $43(46.7)$ & $92(100.0)$ & \\
\hline \multirow[t]{4}{*}{ Educational status } & Illiterate & $48(55.2)$ & $39(44.8)$ & $87(100.0)$ & 0.528 \\
\hline & Grade 1-4 & $19(45.2)$ & $23(54.8)$ & $42(100.0)$ & \\
\hline & Grade 5-8 & $27(49.1)$ & $28(50.9)$ & $55(50.0)$ & \\
\hline & Grade 9-10/11-12 & $7(38.9)$ & $11(61.1)$ & $18(100.0)$ & \\
\hline \multirow[t]{6}{*}{ Main occupation } & Private business & $12(54.5)$ & $10(45.5)$ & $22(100.0)$ & 0.112 \\
\hline & Government employee & $3(33.3)$ & $6(66.7)$ & $9(100.0)$ & \\
\hline & House wife & $40(47.6)$ & $44(52.4)$ & $84(100.0)$ & \\
\hline & Daily laborer & $38(56.7)$ & $29(43.3)$ & $67(100.0)$ & \\
\hline & Farmer & $8(57.1)$ & $6(42.9)$ & $14(100.0)$ & \\
\hline & Others & 0 & $6(100.0)$ & $6(100.0)$ & \\
\hline \multirow[t]{3}{*}{ Estimated monthly income (ETB) } & $<500$ & $20(45.5)$ & $24(54.5)$ & $44(100.0)$ & 0.266 \\
\hline & $501-1000$ & $57(47.9)$ & $62(52.1)$ & $119(100.0)$ & \\
\hline & $>1000$ & $24(61.5)$ & $15(38.5)$ & $39(100.0)$ & \\
\hline \multirow[t]{2}{*}{ Distance from vector-breeding site } & $<1 \mathrm{~km}$ & 75 (59.5) & $51(40.5)$ & $126(100.0)$ & $0.000^{*}$ \\
\hline & $>1 \mathrm{~km}$ & $26(34.2)$ & $50(65.8)$ & $76(100.0)$ & \\
\hline \multirow[t]{2}{*}{ House type } & Mud plastered & $89(47.8)$ & $97(52.2)$ & $186(100.0)$ & $0.037^{*}$ \\
\hline & Break wall & $12(75.0)$ & $4(25.0)$ & $16(100.0)$ & \\
\hline \multirow[t]{2}{*}{ ITN } & Yes & $60(46.9)$ & $68(53.1)$ & $128(100.0)$ & 0.243 \\
\hline & No & $41(55.4)$ & $33(44.6)$ & $74(100)$ & \\
\hline \multirow[t]{2}{*}{ IRS } & Yes & $86(49.4)$ & $88(50.6)$ & $174(100.0)$ & 0.684 \\
\hline & No & 15 (53.6) & $13(46.4)$ & $28(100.0)$ & \\
\hline \multirow[t]{2}{*}{ Presence of domestic animal(s) } & Yes & $57(55.3)$ & $46(44.7)$ & $103(100.0)$ & 0.122 \\
\hline & No & $44(44.4)$ & 55 (55.6) & 99 (100.0) & \\
\hline
\end{tabular}

*Significant at $p<0.05 ; \mathrm{ETB}=$ Ethiopian Birr.

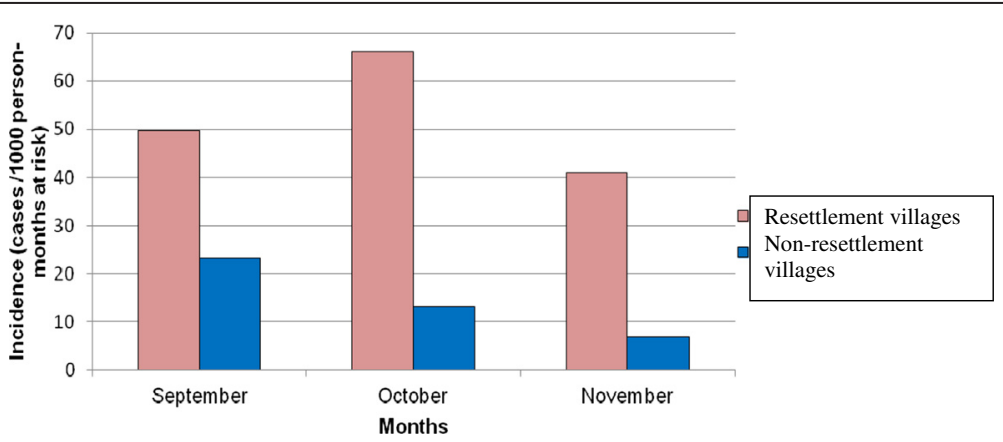

Figure 2 Plasmodium falciparum malaria incidence in resettlement and non-resettlement villages, Jimma town, Southwest Ethiopia (September - November 2013). 
Table 2 Estimates of a three level generalized linear mixed regression model (GLMM) for comparison of malaria incidence between resettlement and non-resettlement villages, Jimma town, Southwest Ethiopia (September - November 2013)

\begin{tabular}{|c|c|c|c|c|}
\hline Parameters & Exponentiated estimate (OR) & Standard error & $95 \% \mathrm{Cl}$ & $p$-value \\
\hline \multicolumn{5}{|l|}{ Village type } \\
\hline Non-resettlement (Ref.) & 1.00 & & & \\
\hline Resettlement & 2.807 & 0.427 & $1.22-6.48$ & $0.016^{*}$ \\
\hline Month & 1.210 & 0.179 & $0.85-1.72$ & 0.286 \\
\hline Age & 1.010 & 0.009 & $0.99-1.03$ & 0.316 \\
\hline \multicolumn{5}{|l|}{ Gender } \\
\hline Female (Ref.) & 1.00 & & & \\
\hline Male & 1.185 & 0.303 & $0.65-2.15$ & 0.576 \\
\hline \multicolumn{5}{|c|}{ Distance of $\mathrm{HH}$ from larval breeding site } \\
\hline Greater than 1 km (Ref.) & 1.00 & & & \\
\hline Less than $1 \mathrm{~km}$ & 2.250 & 0.432 & $0.97-5.25$ & 0.060 \\
\hline \multicolumn{5}{|l|}{ Domestic animal } \\
\hline No (Ref.) & 1.00 & & & \\
\hline Yes & 1.424 & 0.350 & $0.72-2.83$ & 0.313 \\
\hline \multicolumn{5}{|l|}{ House type } \\
\hline No holes on the walls (Ref.) & 1.00 & & & \\
\hline Holes on the walls & 3.186 & 0.537 & $1.11-9.14$ & $0.031^{*}$ \\
\hline Family size & 0.759 & 0.115 & $0.61-0.95$ & $0.017^{*}$ \\
\hline \multicolumn{5}{|l|}{ ITNs } \\
\hline Available (Ref.) & 1.00 & & & \\
\hline Not available & 1.250 & 0.335 & $0.65-2.41$ & 0.506 \\
\hline \multicolumn{5}{|l|}{ IRS } \\
\hline Sprayed (Ref.) & 1.00 & & & \\
\hline Not sprayed & 0.935 & 0.488 & $0.36-2.43$ & 0.890 \\
\hline
\end{tabular}

*Significant at $\mathrm{p}<0.05 ; \mathrm{OR}=$ odds ratio; $95 \% \mathrm{Cl}=95 \%$ confidence interval.

main predictors of Plasmodium infection. The risk of Plasmodium infection among those who lived in houses with holes on the walls was three times higher as compared to those who lived in houses with no holes on the walls $(\mathrm{OR}=$ 3.18, 95\% CI: 1.11-9.14). Family size also showed association with Plasmodium infection. For a decrease in family size by one, the odds of Plasmodium infection decreased by $24 \%$ $(\mathrm{OR}=0.7589,95 \% \mathrm{CI}: 0.61-0.95)$. Other covariates assessed did not show significant effect at $5 \%$ level of significance.

\section{Adult mosquito abundance}

Table 3 presents anopheline mosquito abundance, species composition and distribution. Overall, 1,912 female anopheline mosquitoes belonging to four species (An. gambiae s. l., Anopheles coustani complex, Anopheles pharoensis and Anopheles squamosus) were collected over the study period. Anopheles gambiae s.l. was the most predominant species (86.6\%). The majority (76.3\%) of anopheline mosquitoes were collected from the resettlement villages.

Mean monthly indoor and outdoor density of Anopheles gambiae s.l. in the two villages is shown in Figure 3. Overall monthly density of indoor host seeking An. gambiae s.l. in the study area ranged from 1.96 to 15 per trap/night with mean density of 8.21 per trap/night. Mean indoor host seeking An. gambiae s.l density in the resettlement and nonresettlement villages was 13.38 and 3.04 per trap/night, respectively. The difference in mean density of host seeking An. gambiae s.l between the two villages was significant $(\mathrm{F}=30.9, \mathrm{p}=0.0026)$. Mean indoor resting density of $A n$. gambiae s.l. was significantly higher in resettlement villages (2.8 per house/day) than non-resettlement villages (0.99 per house/day) $(\mathrm{F}=13.2, \mathrm{p}=0.015)$. Similarly, significantly higher mean outdoor host seeking density of An. gambiae S. l. was recorded in the resettlement villages $(F=18$, $\mathrm{p}=0.008)$.

\section{Sporozoite rates}

A total of 1,510 anopheline mosquitoes were tested for Plasmodium CSPs. Of these, 23 An. gambiae s.l. specimens were positive for CSPs, of which 19 (82.6\%) were positive for $P$. falciparum and 4 (17.4\%) were positive for $P$. vivax (Table 4). In addition, a single specimen of 
Table 3 Anopheline mosquito species composition, abundance and distribution in resettlement and non-resettlement villages, Jimma town, Southwest Ethiopia (June - November 2013)

\begin{tabular}{|c|c|c|c|c|c|}
\hline \multirow[t]{3}{*}{ Village type } & \multirow{3}{*}{$\begin{array}{l}\text { Anopheline } \\
\text { species }\end{array}$} & \multicolumn{3}{|c|}{ Collection method } & \multirow{3}{*}{$\begin{array}{l}\text { Total } \\
\text { n (\%) }\end{array}$} \\
\hline & & LTCs (Indoor) & LTCs (Outdoor) & PSCs & \\
\hline & & n (\%) & n (\%) & n (\%) & \\
\hline \multirow[t]{4}{*}{ Resettlement $(n=1458)$} & An. gambiae s.l & $642(44.0)$ & $332(22.8)$ & $332(22.8)$ & $1306(89.6)$ \\
\hline & An. coustani & $39(2.7)$ & $47(3.2)$ & $11(0.8)$ & $97(6.7)$ \\
\hline & An. pharoensis & $29(2.0)$ & $12(0.8)$ & $6(0.4)$ & $47(3.2)$ \\
\hline & An. squamosus & $1(0.1)$ & $7(0.5)$ & 0 & $8(0.5)$ \\
\hline \multirow[t]{4}{*}{ Non-resettlement $(n=454)$} & An. gambiae s.l & $146(32.2)$ & $84(18.5)$ & $119(26.2)$ & 349 (76.9) \\
\hline & An. coustani & $31(6.8)$ & $32(7.0)$ & $21(4.6)$ & $84(18.5)$ \\
\hline & An. pharoensis & $3(0.7)$ & $1(0.2)$ & $7(1.5)$ & $11(2.4)$ \\
\hline & An. squamosus & $4(0.9)$ & $6(1.3)$ & 0 & $10(2.2)$ \\
\hline \multirow[t]{4}{*}{ Overall $(n=1912)$} & An. gambiae s.l & $788(41.2)$ & $416(21.8)$ & $451(23.6)$ & 1655 (86.6) \\
\hline & An. coustani & $70(3.7)$ & $79(4.1)$ & $32(1.7)$ & $181(9.5)$ \\
\hline & An. pharoensis & $32(1.7)$ & $13(0.7)$ & $13(0.7)$ & $58(3.0)$ \\
\hline & An. squamosus & $5(0.3)$ & $13(0.7)$ & 0 & $18(0.9)$ \\
\hline
\end{tabular}

Key: $\mathrm{n}=$ Number of anophelines collected; LTCs = Light trap catches; PSCs = Pyrethrum spray catches.

An. coustani was also positive for P. falciparum (not PCR confirmed). Overall Plasmodium sporozoite rate for An. gambiae s.l. was $1.8 \%$. The sporozoite rates of $P$. falciparum and P. vivax for An. gambiae s.l. were $1.5 \%$ and $0.3 \%$, respectively. Plasmodium sporozoite rates for $A n$. gambiae s.l. from indoor LTCs, outdoor LTCs and PSCs were $2.0 \%, 1.9 \%$ and $1.5 \%$, respectively. Infectivity rates for An. gambiae s.l. in the resettlement and nonresettlement villages were $2.1 \%$ and $0.72 \%$, respectively and the difference was significant $(\mathrm{F}=9.4, \mathrm{p}=0.028)$.

\section{Entomological inoculation rates (EIRs)}

Table 5 shows the entomological inoculation rates of $A n$. gambiae s.l. in the study area. Overall the EIRs of An. gambiae s.l. for $P$. falciparum and $P$. vivax were 6.55 and 1.46 infective bites/person/month, respectively. The EIR of $A n$. gambiae s.l. for $P$. falciparum in resettlement and nonresettlement villages was 13.1 and 0 infective bites/person/ month, respectively, while EIR of An. gambiae s.l. for $P$. vivax EIRs in resettlement and non-resettlement villages was 2.9 and 0 infective bites/person/month, respectively. The difference in P. falciparum EIRs of An. gambiae s.l. between resettlement and non-resettlement villages was significant $(\mathrm{F}=9.9, \mathrm{p}=0.025)$.

\section{Discussion}

This study revealed that malaria incidence and transmission intensity was significantly higher in the resettlement villages as compared to the non-resettlement villages. Individuals living in resettlement villages were three times more likely to have $P$. falciparum infection as compared to individuals living in non-resettlement villages. The higher incidence of $P$. falciparum infection in resettlement villages might be due to suitable mosquito breeding sites created as a result of the resettlement [19]. Moreover, differences in housing structures in the two villages could also attribute for the observed difference in P. falciparum malaria incidence. The higher incidence of $P$. falciparum in the resettlement villages calls for malaria control intervention strategies during resettlement schemes.

Other studies have also reported increase in malaria incidence and an increase in malaria affected people as a result of population resettlement [20]. In studies conducted in Brazil, reemergence of malaria was noted as a result of resettlement $[21,22]$. Similarly, in another study conducted in Somalia [23], a significant increase in malaria prevalence was reported following influx of nonimmune people in to malaria endemic areas. Earlier reports from Pawe resettlement scheme, North-west Ethiopia also showed similar findings [8,10,24]. Recently, Loha and Lindtjørn [25] also reported that temporary residents and visitors experienced higher episodes of $P$. falciparum compared to permanent residents which is in agreement with the findings of the current study.

The socio-demographic and socio-economic data indicated that the resettlement and non-resettlement study communities were similar with respect to age, sex, educational status, occupation of heads of the households, monthly income, family size, presence of domestic animals, ITN ownership and IRS. But, nearly three quarters of the households in the resettlement villages were located less than $1 \mathrm{~km}$ from vector-breeding sites. Moreover, $12 \%$ and $4 \%$ of the houses in the resettlement and non-resettlement villages were with holes on the walls, respectively. The overall malaria prevalence (6.3\%) recorded in this study is slightly higher than the previous report from Jimma town, 

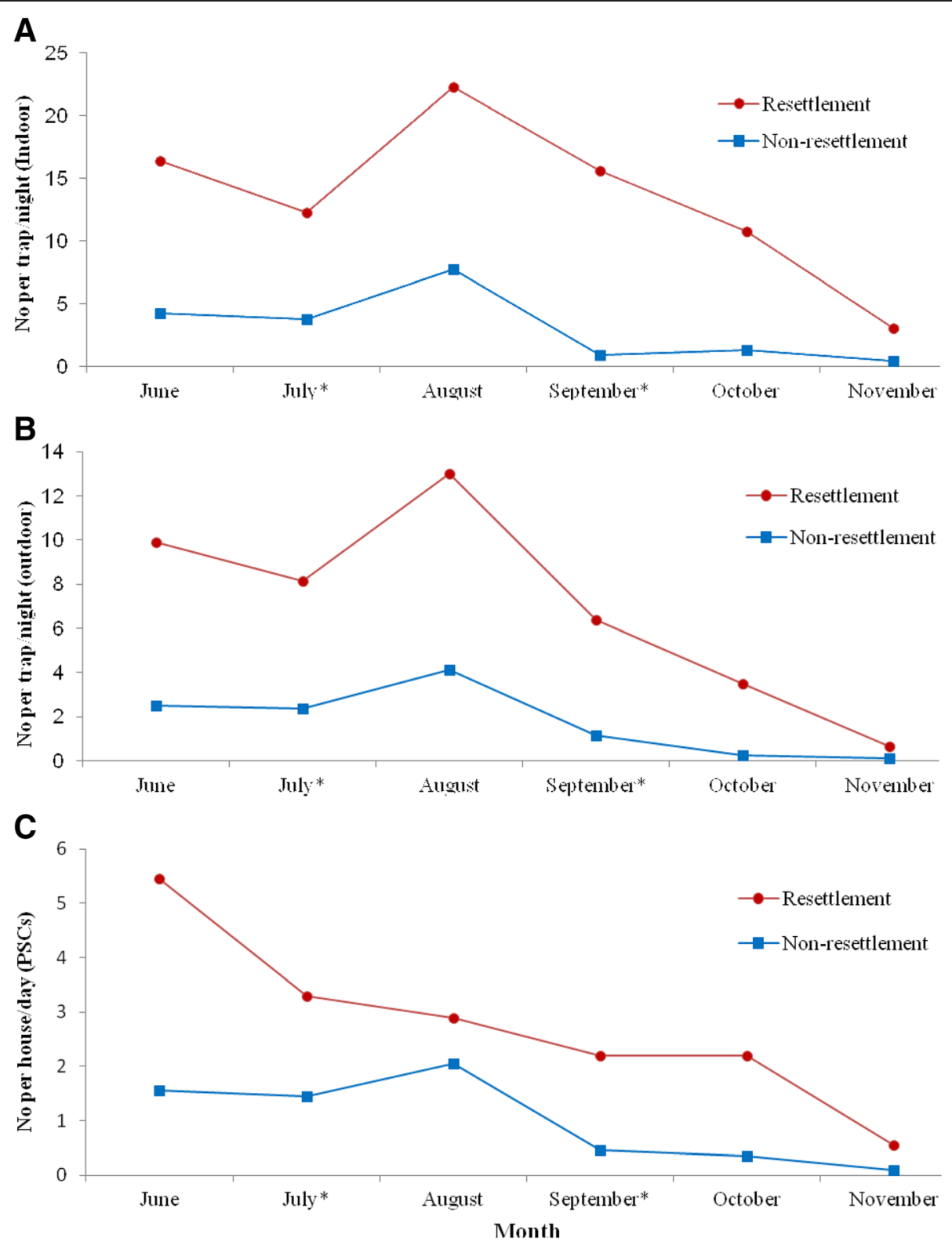

Figure 3 Mean monthly indoor and outdoor Anopheles gambiae s.l density in resettlement and non-resettlement villages, Jimma town, Southwest Ethiopia (June - November 2013). (A) Indoor host seeking mosquito density. (B) Outdoor host seeking mosquito density. (C) Indoor resting mosquito density.

southwestern Ethiopia (5.22\%) [11]. This could be due to the difference in time the two studies were conducted. The current study was conducted from August to October, which is part of the peak malaria transmission season in the study setting while the later was conducted from April to May. Moreover, environmental changes as a result of resettlement might have created potential breeding habitats for malaria vectors in the suburbs of the town. The present study was also conducted in suburbs of the town where resettlement occurred. Higher malaria incidence in peripheral areas than central areas of the same town was also reported in Burkina Faso [26].

In this study, the P. falciparum incidence $(33.5 / 1,000$ person-months at risk) is higher than malaria incidence of 3.6/10,000 person-weeks and 14.6 cases/1000 personmonths at risk reported from Chano Mille [24] and Gilgel-Gibe hydropower area, southwestern Ethiopia [27], respectively. The difference could be due to differences in environmental factors and season. In contrast, $P$. falciparum incidence recorded in this study is lower 
Table 4 Sporozoite infection rates of anopheles mosquitoes collected from resettlement and non-resettlement villages, Jimma town, Southwest Ethiopia (June-November 2013)

\begin{tabular}{|c|c|c|c|c|c|c|c|}
\hline \multirow{4}{*}{$\begin{array}{l}\text { Collection } \\
\text { method }\end{array}$} & \multirow{4}{*}{$\begin{array}{l}\text { Anopheline } \\
\text { species }\end{array}$} & \multicolumn{6}{|c|}{ Village type } \\
\hline & & \multicolumn{3}{|c|}{ Resettlement } & \multicolumn{3}{|c|}{ Non-resettlement } \\
\hline & & \multirow{2}{*}{$\begin{array}{l}\text { Number } \\
\text { tested }\end{array}$} & \multirow{2}{*}{$\begin{array}{l}P f \\
\mathrm{n}(\%)\end{array}$} & \multirow{2}{*}{$\begin{array}{l}P v \\
\mathrm{n}(\%)\end{array}$} & \multirow{2}{*}{$\begin{array}{l}\text { Number } \\
\text { tested }\end{array}$} & \multirow{2}{*}{$\begin{array}{l}P f \\
\mathrm{n}(\%)\end{array}$} & \multirow{2}{*}{$\begin{array}{l}P v \\
\mathrm{n}(\%)\end{array}$} \\
\hline & & & & & & & \\
\hline \multirow[t]{4}{*}{ LTCs (Indoor) } & An. gambiae s.l & 450 & $9(2.0)$ & $2(0.4)$ & 102 & 0 & 0 \\
\hline & An. coustani & 35 & 0 & 0 & 27 & 0 & 0 \\
\hline & An. pharoensis & 27 & 0 & 0 & 3 & 0 & 0 \\
\hline & An. squamosus & 1 & 0 & 0 & 4 & 0 & 0 \\
\hline \multirow[t]{4}{*}{ LTCs (Outdoor) } & An. gambiae s.l & 248 & $4(1.6)$ & 0 & 75 & $1(1.3)$ & $1(1.3)$ \\
\hline & An. coustani & 41 & 0 & 0 & 29 & 0 & 0 \\
\hline & An. pharoensis & 12 & 0 & 0 & 1 & 0 & 0 \\
\hline & An. squamosus & 7 & 0 & 0 & 6 & 0 & 0 \\
\hline \multirow[t]{3}{*}{ PSCS } & An. gambiae s.l & 297 & $5(1.7)$ & $1(0.3)$ & 99 & 0 & 0 \\
\hline & An. coustani & 13 & $1(7.7)$ & 0 & 19 & 0 & 0 \\
\hline & An. pharoensis & 7 & 0 & 0 & 7 & 0 & 0 \\
\hline \multirow[t]{4}{*}{ Overall } & An. gambiae s.l & 995 & $18(1.8)$ & $3(0.3)$ & 276 & $1(0.36)$ & $1(0.36)$ \\
\hline & An. coustani & 89 & $1(1.1)$ & 0 & 75 & 0 & 0 \\
\hline & An. pharoensis & 46 & 0 & 0 & 11 & 0 & 0 \\
\hline & An. squamosus & 8 & 0 & 0 & 10 & 0 & 0 \\
\hline
\end{tabular}

Key: $P f=P$. falciparum, $P v 210=P$. vivax $; \mathrm{n}=$ Number of anopheline mosquitoes positive for CSPs; Number in parenthesis indicate sporozoite rates.

than the incidence $(90.5 / 1,000$ population at risk) reported from Adama, central Ethiopia [28]. In the later, malaria incidence was determined from the total number of infections ( $P$. falciparum, $P$. vivax and mixed infection, which might have contributed to the observed difference.

The entomological survey of this study showed that $A n$. gambiae s.l. was the most predominant species in the study setting, accounting for $86.6 \%$ of all collected anopheline mosquitoes. Other similar studies also documented

Table 5 Monthly sporozoite infection rates and entomological inoculation rates (EIRs) of An. gambiae s.l. collected using LTCs from resettlement and nonresettlement villages, Jimma town, Southwest Ethiopia (June-November 2013)

\begin{tabular}{|c|c|c|c|c|c|c|c|c|}
\hline \multirow[t]{3}{*}{ Month } & \multicolumn{8}{|c|}{ Village type } \\
\hline & \multicolumn{4}{|c|}{ Resettlement } & \multicolumn{4}{|c|}{ Non-resettlement } \\
\hline & PfSR & PfEIR & PvSR & PvEIR & PfSR & PfEIR & PvSR & PvEIR \\
\hline June & 2.4 & 19.0 & 0 & 0 & 0 & 0 & 0 & 0 \\
\hline July & 1.3 & 7.9 & 1.3 & 7.9 & 0 & 0 & 0 & 0 \\
\hline August & 0.7 & 8.2 & 0.7 & 8.2 & 0 & 0 & 0 & 0 \\
\hline September & 4.1 & 30.5 & 0 & 0 & 0 & 0 & 0 & 0 \\
\hline October & 3.2 & 17.0 & 0 & 0 & 0 & 0 & 0 & 0 \\
\hline November & 0 & 0 & 0 & 0 & 0 & 0 & 0 & 0 \\
\hline
\end{tabular}

Key: PfSR $=$ P.falciparum sporozoite rate; $P f E I R=P$. falciparum entomological inoculation rate; $P V E I R=P$. vivax entomological inoculation rate. that An. gambiae s.l. is the most predominant species in Ethiopia [27,29,30].

Higher density of An. gambiae s.l. was recorded in the resettlement villages as compared to the non-resettlement villages. Indoor host-seeking density of An. gambiae s.l. was four times higher in resettlement villages. In addition, outdoor host-seeking density of An. gambiae s.l. was higher in the resettlement villages. These differences could be due to the presence of abundant temporary vector breeding sites in resettlement villages. Cox et al. [19] also reported that human settlement initially favors the multiplication of mosquito breeding sites and the perennial presence of high densities of mosquitoes as housing is quite often constructed faster than the drainage system. New settlers dug the land around their houses either for plastering or brick-making, resulting in pits which could create potential mosquito breeding sites hence increase vector density in areas with resettlement schemes [31]. Higher P. falciparum sporozoite rate in this study might have led to the occurrence of higher $P$. falciparum malaria cases than $P$. vivax in the study setting. Other studies also documented increased Plasmodium sporozoite rate with increased malaria incidence in southwestern Ethiopia [25,29].

Plasmodium sporozoite rate and mean monthly EIR of P. falciparum for An. gambiae s.l. were significantly higher in the resettlement villages. The higher EIRs observed in the resettlement villages indicate that malaria transmission intensity was higher in those villages. Heterogeneity in 
anopheline mosquito infectivity rate among villages was also reported in studies conducted in Ghana [32], Burkina Faso [25] and Sudanian area of Senegal [33]. Small-area variation in Plasmodium infectivity rates can be explained by the spatial heterogeneity of exposures to infection that is, human vector contacts.

The annual EIR of An. gambiae s.l. recorded in the present study is higher than the EIR reported from southern, central and south-central Ethiopia, with annual EIRs of 17.1, $34.8,3.7$ infective bites per year, respectively $[29,34,35]$. The difference might be due to difference in seasons of mosquito sampling. Anopheline mosquitoes were sampled during peak malaria transmission season in the present study unlike others which covered all seasons of the year. Moreover, difference in environmental factors between the study areas might have contributed to the difference in EIRs.

In addition, a single specimen of An. coustani was positive for P. falciparum CSP (not PCR confirmed). Although this species was not yet incriminated as vector of malaria in Ethiopia, it is a complementary vector elsewhere in Africa [36,37]. This species is considered as suspected vector in Ethiopia but never reported to have a role in malaria transmission.

\section{Conclusion}

The study communities from resettlement villages were at higher risk of Plasmodium infection as compared to communities from non-resettlement villages. Malaria transmission intensity was also higher in the resettlement villages. Appropriate use of the existing malaria control intervention tools such as ITNs and IRS should be in place and scaled-up during resettlement schemes. Health education and environmental management supported by active community mobilization and participation is recommended to eliminate temporary and/or permanent vector-breeding sites in such new settlement areas. Further studies on the infectivity of An. coustani should be carried out using molecular diagnostics.

\section{Competing interests}

The authors declare that they have no competing of interests.

\section{Authors' contributions}

TD and DY conceived the study; TD, DY and AZ designed the study protocol; TD involved in data acquisition; DY, AZ, AG, YH, KE, EZ, DE and KT supervised data collection and carried out data quality control; TD and BB involved in data entry and analysis. TD and EZ drafted the manuscript; DY critically reviewed the manuscript. All authors read and approved the final manuscript.

\section{Acknowledgements}

The authors would like to thank all entomology technicians of Field Vector Biology Laboratory of Jimma University for their excellent technical support, and study subjects participating in the study are highly acknowledged. We are also grateful to Jimma Town Department of Health for providing anti-malarial drugs to treat positive cases encountered during the study.

\section{Funding}

This work was financially supported by Jimma University Research and Publication Office.

\section{Author details}

${ }^{1}$ Department of Medical Laboratory Sciences and Pathology, College of Public Health and Medical Sciences, Jimma University, Jimma, Ethiopia. ${ }^{2}$ Department of Sociology, College of Social Sciences, Jimma University, Jimma, Ethiopia. ${ }^{3}$ Department of Health Services Management, College of Public Health and Medical Sciences, Jimma University, Jimma, Ethiopia. ${ }^{4}$ Department of Environmental Health and Technology, College of Public Health and Medical Sciences, Jimma University, Jimma, Ethiopia. ${ }^{5}$ Department of Statistics, College of Natural Sciences, Jimma University, Jimma, Ethiopia.

Received: 2 November 2014 Accepted: 22 December 2014 Published online: 28 January 2015

\section{References}

1. Deressa W, Hailemariam D, Ali A. Economic costs of epidemic malaria to households in rural Ethiopia. Trop Med Int Health. 2007;12:1148-56.

2. WHO. World Malaria Report 2010. Geneva, Switzerland: World Health Organization; 2010.

3. FMoH. National Malaria Strategic Plan 2014-2020. Addis Ababa Ethiopia: Federal Democratic Republic of Ethiopia Ministry of Health; 2014.

4. FMoH. Ethiopia National Malaria Indicator Survey 2011 Technical Summary. Addis Ababa, Ethiopia: Federal Democratic Republic of Ethiopia Ministry of Health; 2012.

5. Shargie EB, Ngondi J, Graves PM, Getachew A, Hwang J, Gebre T, et al. Rapid increase in ownership and use of long-lasting insecticidal nets and decrease in prevalence of malaria in three regional states in Ethiopia (2006-2007). J Trop Med 2010, doi:10.1155/2010/750978.

6. Jima D, Wondabeku M, Alemu A, Teferra A, Awel N, Deressa W, et al. Analysis of malaria surveillance data in Ethiopia: what can be learned from the integrated disease surveillance and response system? Malar J. 2012;11:330

7. Otten M, Aregawi M, Were W, Karama C, Medhin A, Bekele W, et al. Initial evidence of reduction of malaria cases and deaths in Rwanda and Ethiopia due to rapid scale-up of malaria prevention and treatment. Malar J. 2012;8:14

8. Kloos H. Health aspects of resettlement in Ethiopia. Soc Sci Med. 1990;30:643-56.

9. Nega A, Meskal F. Population migration and malaria transmission in Ethiopia. In: Malaria and economic development in Africa, a cross-sectional approach. Washington, D.C. USA: American Association for the Advancement of Science; 1991. p. 181-9.

10. Alamerew D, Equbazg G. Determinants of symptomatic and asymptomatic malaria. Ethiop J Health Dev. 1998;12:69-74.

11. Alemu A, Tsegaye W, Golassa L, Abebe G. Urban malaria and associated risk factors in Jimma town, south-west Ethiopia. Malar J. 2011;10:173.

12. Central Statistical Agency (Federal Democratic Republic of Ethiopia). The 2007 population and housing census of Ethiopia, result for Oromia region. Addis Ababa, Ethiopia: Central Statistical Agency; 2010.

13. Cheesbrough M. District Laboratory Practice in Tropical Countries, Part I. 2nd ed. Cambridge: Cambridge University Press; 2009. p. 196-8.

14. Gillies M, Coetzee M. A Supplement to the anopheline of Africa South of the Sahara (Afrotropical Region). Johannesburg, South Africa: Publication of the South African Institute for Medical Research; 1987.

15. Verone G. Outline for the determination of malaria mosquitoes in Ethiopia. Part I. Adult female anopheles mosquitoes in Ethiopia. Mosq News. 1962;2:37-49.

16. Beier J, Perkins $P$, Wirtz R, Whitmire RE, Muqambi M, Hockmeyer WT. Field evaluation of an enzyme-linked immunosorbent assay (ELISA) for Plasmodium falciparum sporozoite detection in anopheline mosquitoes from Kenya. Am J Trop Med Hyg. 1987;36:459-68.

17. Wirtz RA, Sattabongkot J, Hall T, Burkot TR, Rosenberg R. Development and evaluation of an enzyme-linked immunosorbent assay for Plasmodium vivax-VK247 sporozoites. J Med Entomol. 1992;29:854-7.

18. Drakeley C, Schellenberg D, Kihonda J, Sousa CA, Arez AP, Lopes D, et al. An estimation of the entomological inoculation rate for Ifakara: a semi-urban area in a region of intense malaria transmission in Tanzania. Trop Med Int Health. 2003;8:767-74 
19. Cox JSH, Mouchet J, Bradley DJ. Determinants of malaria in Sub-Saharan Africa. In: Casman EA, Dowlatabadi H, editors. The Contextual Determinants of Malaria. Washington DC: Resources for future press; 2002. p. 167-86.

20. Woube M. Geographical distribution and dramatic increases in incidences of malaria: consequences of the resettlement scheme in Gambela, SW Ethiopia. Indian J Malar. 1997;34:140-63.

21. Marques AC. Migrations and the dissemination of malaria in Brazil. Mem Inst Oswaldo Cruz. 1986;81:17-30.

22. Ferreira IM, Yokoo EM, Souza-Santos R, Galvão ND, Atanaka-Santos M. Factors associated with the incidence of malaria in settlement areas in the district of Juruena, Mato Grosso state, Brazil. Cien Saude Colet. 2012;17:2415-24

23. Warsame M. Impact of population movement on malaria transmission in Somalia. In: Malaria and Development in Africa: a Cross-Sectoral Approach American Association for the Advancement of Science, sub-Saharan Africa Programme. 1991. p. 217-21.

24. Woldemeskel G. The consequences of resettlement in Ethiopia. African Affairs. 1989;88:359-74.

25. Loha $\mathrm{E}$, Lindtjørn B. Predictors of Plasmodium falciparum malaria incidence in Chano Mille, South Ethiopia: a longitudinal study. Am J Trop Med Hyg. 2012:87:450-9.

26. Wang S-J, Lengeler C, Smith TA, Vounatsou P, Diadie DA, Pritroipa X, et al. Rapid urban malaria appraisal (RUMA) I: Epidemiology of urban malaria in Ouagadougou. Malar J. 2005;4:43.

27. Yewhalaw D, Getachew Y, Tushune K, W/Michael K, Kassahun W, Duchateau $L$, et al. The effect of dams and seasons on malaria incidence and Anopheles abundance in Ethiopia. BMC Infect Dis. 2013;13:161.

28. Peterson I, Borrell LN, El-Sadr W, Teklehaimanot A. Individual and household level factors associated with malaria incidence in a highland region of Ethiopia: A multilevel analysis. Am J Trop Med Hyg. 2009;80:103-11.

29. Massebo F, Balkew M, Gebre-Michael T, Lindtjørn B. Entomologic inoculation rates of Anopheles arabiensis in Southwestern Ethiopia. Am J Trop Med Hyg. 2013:89:466-73.

30. Massebo F, Balkew M, Gebre-Michael T, Lindtjørn B. Blood meal origins and insecticide susceptibility of Anopheles arabiensis from Chano in South-West Ethiopia. Parasit Vectors. 2013;6:44.

31. Carlson JC, Byrd BD, Omlin FX. Field assessments in western Kenya link malaria vectors to environmentally disturbed habitats during the dry season. BMC Public Health. 2004;4:33.

32. Kreuels B, Kobbe R, Adjei S, Kreuzberg C, Von Reden C, Bäter K, et al. Spatial variation of malaria incidence in young children from a geographically homogeneous area with high endemicity. J Infect Dis. 2008;197:85-93.

33. Niang EHA, Touré A, Ngom EHM, Konate L, Faye O, Diallo M, et al. Malaria transmission pattern in an area selected for clinical trials in the Sudanian area of Senegal (West Africa). J Trop Med. 2013;2013:Article ID 907375.

34. Kibret S, Wilson GG, Tekie H, Petros B. Increased malaria transmission around irrigation schemes in Ethiopia and the potential of canal water management for malaria vector control. Malar J. 2014;13:360.

35. Animut A, Balkew M, Gebre-Michael T, Lindtjørn B. Blood meal sources and entomological inoculation rates of anophelines along a highland altitudinal transect in south-central Ethiopia. Malar J. 2013;12:76.

36. Mwangangi JM, Muturi EJ, Muriu SM, Nzovu J, Midega JT, Mbogo C. The role of Anopheles arabiensis and Anopheles coustani in indoor and outdoor malaria transmission in Taveta District, Kenya. Parasit Vectors. 2013;6:14

37. Antonio-Nkondjio C, HKerah C, Simard F, Awono-Ambene P, Chouaibou M, Tchuinkam T, et al. Complexity of the malaria vectorial system in Cameroon: contribution of secondary vectors to malaria transmission. J Med Entomol. 2006;43:1215-21.

\section{Submit your next manuscript to BioMed Central and take full advantage of:}

- Convenient online submission

- Thorough peer review

- No space constraints or color figure charges

- Immediate publication on acceptance

- Inclusion in PubMed, CAS, Scopus and Google Scholar

- Research which is freely available for redistribution 